\section{Estudo soroepidemiológico da cisticercose humana em um município do Estado do Piauí, Região Nordeste do Brasil}

\author{
Seroepidemiological survey of human \\ cysticercosis in a municipality of Piaui \\ State, Northeast Brazil
}

\author{
Alberto Novaes Ramos Jr. 1 \\ Heloísa Werneck de Macedo ${ }^{2}$ \\ Marcelo Campos Rodrigues 3 \\ Regina Helena Saramago Peralta 2 \\ Nicodemos Alves de Macedo 4 \\ Margareth da Cunha Marques 2 \\ Jair Rodrigues Alves 5 \\ Arly de Negreiros Paes 5 \\ José Adail Fonseca de Castro 3 \\ Adauto José Gonçalves Araújo 6 \\ José Mauro Peralta 7
}

1 Departamento de Saúde Comunitária, Universidade Federal do Ceará, Fortaleza, Brasil.

2 Departamento de Patologia, Universidade Federal Fluminense, Niterói, Brasil.

3 Departamento de Microbiologia e Parasitologia, Universidade Federal do Piauí,

Teresina, Brasil.

${ }^{4}$ Departamento de Clínica e Cirurgia Veterinária, Universidade Federal do Piauí, Teresina, Brasil. 5 Universidade Estadual do Piauí, Teresina, Brasil. 6 Escola Nacional de Saúde Pública, Fundação Oswaldo Cruz, Rio de Janeiro, Brasil. 7 Instituto de Microbiologia, Universidade Federal do Rio de Janeiro, Rio de Janeiro, Brasil.

Correspondência J. M. Peralta Instituto de Microbiologia, Universidade Federal do Rio de Janeiro. Cidade Universitária, Rio de Janeiro, $R J$ 21941-590, Brasil. peralta@micro.ufrj.br

\begin{abstract}
As part of parasitological studies in the area surrounding the Serra da Capivara National Park, Piaui State, Northeast Brazil, from 1999 to 2001, the current study aimed to evaluate the epidemiological profile of human cysticercosis in the $\mathrm{Mu}$ nicipality of João Costa. Clinical and epidemiological data were obtained, and blood samples were drawn for immunoenzymatic serological tests (ELISA and Western blot), using Taenia crassiceps as the antigen. The first stage, in 1999, investigated 169 individuals with a confirmed history or suspicion of infection/disease involving the teniasis/cysticercosis complex, along with the family members. Some 13.6\% of the individuals were seroreactive for cysticercosis by the ELISA method. The second stage, in 2001, evaluated 92 serum samples of individuals who had been detected as reactive for cysticercosis in the first stage, along with their family members; $24 \%$ of the samples were reactive to cysticercosis by ELISA and 29\% by Western blot. During this same stage a coprological survey was performed with 701 individuals, including volunteers. Prevalence of intestinal parasites was 51\%, with a higher prevalence of protozoans (95\%) than helminths (5\%). The results indicate the endemicity of cysticercosis in the area, in addition to the high frequency of intestinal protozoan infections.
\end{abstract}

Taeniasis; Antibodies; Parasite Diseases

\section{Introdução}

Nos países em desenvolvimento, são observadas freqüências elevadas de parasitoses intestinais e teciduais associadas, resultando em um grande impacto em termos de morbidade e mortalidade 1 . Nessa perspectiva, a neurocisticercose vem representando a principal causa de epilepsia adquirida nesses países, o que evidencia a necessidade de estudos nessas áreas 2 . No Brasil, o seu diagnóstico e o processo de vigilância não são padronizados, o que dificulta a caracterização de sua importância epidemiológica. Além da necessidade de se articularem critérios epidemiológicos, clínicos, sorológicos, radiológicos e histológicos para o estabelecimento do diagnóstico 2 , ressalta-se a inexistência de estudos sistematizados e comparáveis para o estabelecimento de sua distribuição nas diferentes regiões do país ${ }^{3}$. Da mesma forma, em outros países endêmicos, não se dispõem de estimativas precisas da freqüência da cisticercose humana 4.

No Brasil, os dados disponíveis revelam que os estados das regiões Sul, Sudeste e CentroOeste são os de maior relevância para a cisticercose humana 5. Os Estados de São Paulo, Rio de Janeiro, Paraná, Minas Gerais, Espírito Santo e Goiás são considerados como áreas endêmicas de neurocisticercose, observando-se presença ocasional nos Estados da Bahia, Maranhão, Pernambuco, Ceará, Paraíba e Rio Gran- 
de do Norte 6 . Entretanto, essa situação não reflete a realidade epidemiológica do Brasil, uma vez que no Piauí, por exemplo, o complexo teníase-cisticercose tem sido pouco investigado 7 .

Visando contribuir para o panorama epidemiológico da cisticercose humana no Brasil, este trabalho integra os estudos sobre as parasitoses intestinais desenvolvidos na população do entorno do Parque Nacional Serra da Capivara, região semi-árida do Nordeste do Brasil, no sudeste do Estado do Piauí ${ }^{8}$. Este trabalho tem como objetivo estudar o perfil epidemiológico da neurocisticercose na população do Município de João Costa, localizada no entorno do referido parque. Em paralelo, pretende-se determinar a prevalência das parasitoses intestinais e principalmente observar se infecções por Taenia estão presentes nessa população.

\section{Material e métodos}

\section{Área estudada}

O Município de João Costa está localizado na microrregião de São João do Piauí, Alto Médio Canindé (sudeste piauiense), distante da capital, Teresina, $550 \mathrm{~km}$. Integra a área do Parque Nacional Serra da Capivara, conhecido por seus mais de 450 sítios arqueológicos e pelo trabalho de preservação do ecossistema da caatinga, desenvolvido pela Fundação Museu do Homem Americano (FUMDHAM).

De características predominantemente rurais, esse município apresenta uma baixa densidade populacional, com população estimada de 3.090 habitantes no ano 2003, distribuída em uma área de $1.862,9 \mathrm{~km}^{2}$ e que apresenta um nível sócio-econômico-sanitário deficitário 9 Esses dados foram observados por estudos epidemiológicos prévios realizados desde 1999 na área que identificaram como principal atividade, a agropecuária de subsistência, um elevado índice de analfabetismo, precariedade da infra-estrutura básica de saneamento bem como do sistema de saúde local 10 . Observou-se que mais de $90,0 \%$ dos domicílios não possuíam instalações sanitárias, sequer fossas, com circulação do esgoto nas ruas e com concentração de fezes humanas e de animais em quintais e áreas abertas; os animais eram criados soltos, com presença freqüente de suínos nas ruas e dentro das casas em busca de alimentos 10 .

\section{Avaliação epidemiológica}

Os dados do estudo foram obtidos entre os anos de 1999 e 2001. Para a análise do contexto epidemiológico de base da área, utilizaram-se os dados obtidos no estudo sobre a doença de Chagas 10. Para as questões referentes a este estudo, estruturou-se um questionário para se buscarem as informações específicas referentes aos riscos associados à transmissão da teníase e da cisticercose, como origem da água consumida, local de eliminação dos dejetos e de criação de porcos (Tabela 1).

\section{Estudo sorológico}

Com o objetivo de se estabelecer à detecção de anticorpos IgG para cisticercose, o estudo sorológico foi estruturado em dois momentos.

O primeiro momento compreendeu estudos sobre as parasitoses intestinais e sobre a doença de Chagas, realizados em cooperação com a prefeitura local e a FUMDHAM 10. Foram identificados de forma preliminar, através de entrevistas, possíveis casos de cisticercose seja por sinais e sintomas referidos, seja por diagnósticos estabelecidos anteriormente por outros profissionais. Esses casos foram submetidos a uma outra entrevista, que identificou a elevada freqüência de utilização de anticonvulsivantes por pessoas de diferentes faixas etárias, que associavam o uso desse medicamento ao que chamam de "passamento" (tradução popular de fenômenos reconhecidos como desmaio, ausência e crise convulsiva).

No mês de novembro de 1999, 169 pessoas foram avaliadas, sendo 78 (46,0\%) do sexo masculino e 91 (54,0\%) do sexo feminino, com idades variando de 2 a 89 anos, distribuídas em 36 domicílios com média de 4,69 habitantes por domicílio.

Algumas pessoas já eram casos confirmados de neurocisticercose diagnosticada por meio de estudo de imagem em serviços de saúde de outros municípios. Outras eram portadoras de teníase pelo exame parasitológico de fezes que, no entanto, não diferencia Taenia solium de Taenia saginata, e outras eram suspeitas de terem neurocisticercose (pessoas com relato de crises convulsivas, epilepsia, demência, cefaléia crônica, síncope e uso de anticonvulsivantes).

Após a obtenção do consentimento livre e esclarecido, foram coletadas amostras de sangue dessas pessoas e de seus familiares, por venopunção, e submetidas ao teste ELISA para a determinação de anticorpos (IgG) para cisticercose, empregando-se como antígeno glicoproteínas da larva da Taenia crassiceps 11.

No segundo momento, foram analisadas amostras de soro de 92 pessoas selecionadas por terem apresentado sorologia reativa pelo 
Tabela 1

Estudo soroepidemiológico da teníase e cisticercose humana.

\section{Localização}

Entrevistado: Número:

Endereço:

Bairro: Cidade:

\section{População}

\begin{tabular}{lllll}
\hline Num. Nome $\quad$ Idade & Sexo & Natural & Úlima Proc. Escol. & Atividade \\
\hline & Local Ano &
\end{tabular}

\section{Ambiente residencial}

$\square$ Mangue, charco ou alagados a

$\square$ Vazadouro de lixo a

$\square$ Lugar lamacento após chuva

$\square$ Encosta de risco

$\square$ Criação de porcos na vizinhança
Margem de $\square$ rio ou $\square$ lagoa a m

$\square$ Mata ou matagal a _

$\square$ Lugar sujeito à inundação

$\square$ Horta $\square$ particular $\square$ nas vizinhanças

\section{Moradia}

Acesso:

$\square$ Rua

Pavimentado

Caminho

Quantidade total de cômodos:

Quantidade de banheiros:

$\square$ Ladeira

Quantidade de cômodos para dormir:

Quantidade de vasos sanitários:

Paredes:
$\square$ Madeira
Bruto
Pau-a-pique
Revestido
Tijolo

Cobertura interna (cômodo para dormir)
$\square$ Laje
$\square$ Forro madeira
$\square$ Telha-vã

Piso interno revestido (assoalho, cimento etc.):
$\square$ Nenhum
$\square$ Dormitório
$\square$ Todos os
Banheiro cômodos

\section{5. Água}

Origem:

$\square$ Rede: Freqüência

$\square$ Poço:

Última limpeza:

$\square$ perfurado

$\square$ com tampa

$\square$ com bomba:

$\square$ motor

$\square$ manual

$\square$ Nascente:

$\square$ com proteção profundidade total: m

Tratamento:

$\square$ Filtração

$\square$ Fervura

$\square$ Desinfecção

$\square$ Outros:

Reservatório:

$\square$ Com cobertura

Sem rachaduras $\square$ particular

$\square$ coletivo

última limpeza:

Água de beber:

$\square$ direta
$\square$ armazenada
$\square$ filtrada c/ tampa
$\square$ armazenada s/ tampa

(continua) 
Tabela 1 (continuação)

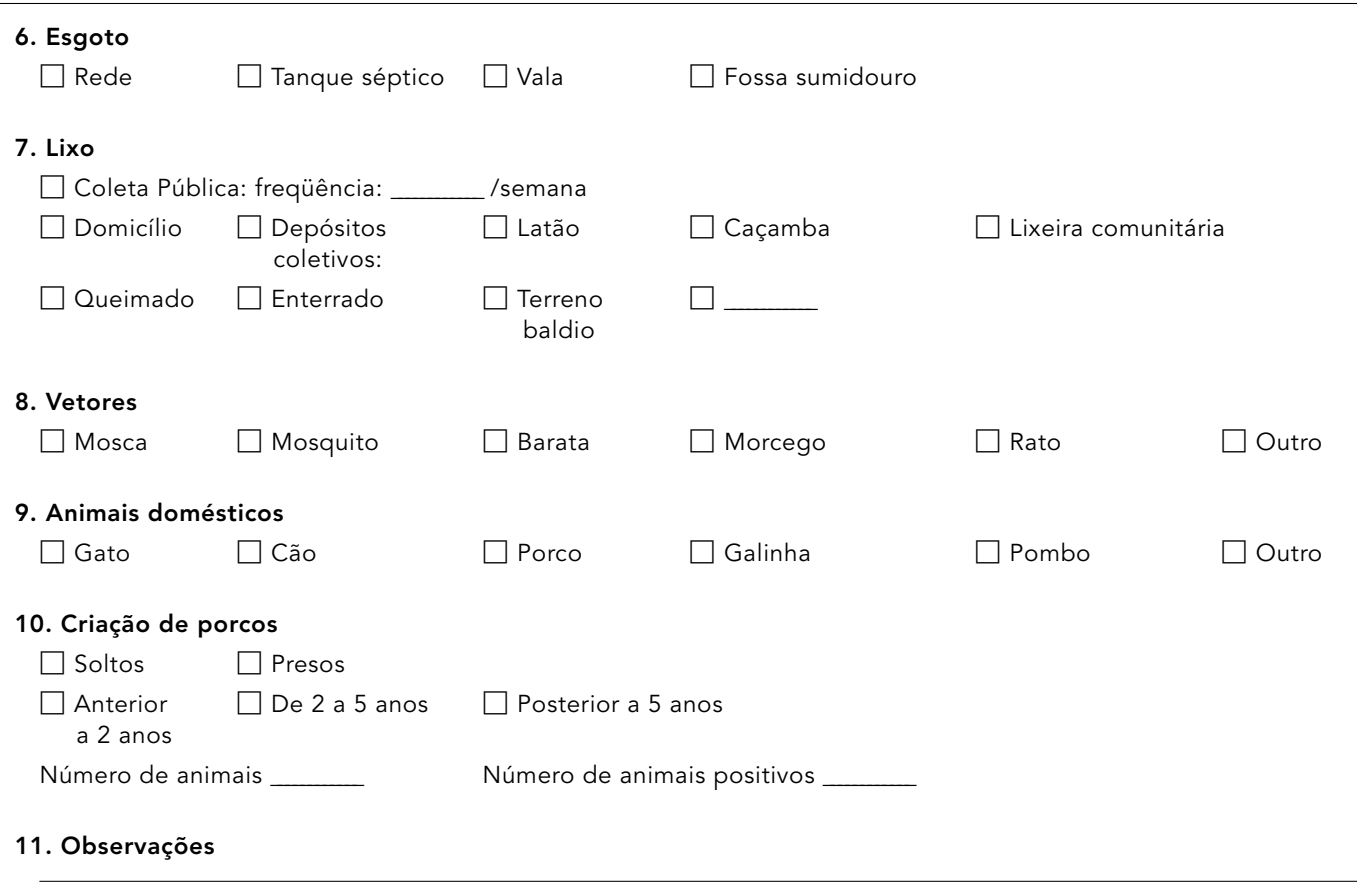

Responsável pelo Levantamento:

método ELISA no primeiro momento, de seus familiares e de pessoas que, nessa ocasião, apresentavam sintomas sugestivos de neurocisticercose (crises convulsivas, epilepsia, demência, cefaléia crônica, síncope). Os métodos empregados foram as reações de ELISA e de Western blot (WB), utilizando como antígeno glicoproteínas da larva da T. crassiceps.

$\mathrm{O}$ antígeno glicoprotéico foi preparado a partir dos cisticercos da T. crassiceps (cepa ORF mantida em camundongos fêmeas BALB/c por inoculação intraperitonial), e a preparação do antígeno bruto foi realizada segundo técnica descrita por Vaz et al. 12. O antígeno foi fracionado por cromatografia de afinidade em coluna de ConA-Sepharose 4B, para separação das glicoproteínas dos cisticercos 13 .

O método ELISA indireto foi padronizado empregando o antígeno glicoprotéico. Os valores do limiar de reatividade foram determinados em um ensaio de padronização, ajustando-se uma distribuição normal. A relação entre o valor do cut-offe as médias dos valores dos controles positivos e negativos foi: cut-off referência $=\mathrm{Xcp}$ $+(\mathrm{Xcp}-\mathrm{Xcn} / 2,3)$. As amostras de soro foram diluídas a 1/100 em PBS contendo 0,3\% de Tween 20 e 5,0\% de leite desnatado (PBS/T/LD).
O método WB foi padronizado empregando o mesmo antígeno e realizado segundo técnica descrita por Teixeira et al. 14, com algumas modificações. A eletroforese (SDS-PAGE) foi feita em gel de poliacrilamida a $12 \%$ empregando o sistema mini-Protean (BioRad, Richmond, Califórnia, Estados Unidos). O antígeno na concentração de $150 \mu \mathrm{g}$ /gel, após corrida eletroforética, foi transferido para membrana de nitrocelulose $(0,2 \mu \mathrm{m})$ e realizada a reação imunoenzimática. As amostras de soro foram diluídas a 1/100, e o conjugado (IgG de cabra anti-IgG humana ligada à fosfatase alcalina) (Biolab Diagnóstico) foi utilizado na diluição de 1/3.000.

Procedeu-se ainda, por meio de amostragem aleatória simples, a avaliação de amostras de fezes de 701 moradores do município (26\% da população local) colhidas em recipientes próprios para o método de sedimentação por centrifugação (Coprotest - NL Comércio Exterior Ltda., São Paulo, Brasil).

\section{Comissão de ética}

Este trabalho foi submetido e aprovado pelo Comitê de Ética em Pesquisa da Universidade Federal do Piauí (CEP/UFPI) pelo Parecer 13/00. 


\section{Análise estatística}

A construção e a análise do banco de dados foram realizadas utilizando-se o programa Epi Info, em sua versão 6.04d. Além da estatística descritiva, foram utilizados o coeficiente de Yule para medir os diferentes graus de associação observados e o teste do qui-quadrado, considerando-se um nível de significância estatística de $5 \%$ em ambos os testes.

\section{Resultados}

No primeiro momento, foram detectados 23 indivíduos $(13,6 \%)$ com teste reagente para cisticerco de T. crassiceps, sendo 14 (8,3\%) do sexo feminino e 9 (5,3\%) do sexo masculino. Das 146 $(86,4 \%)$ pessoas com testes não reagentes, 69 (40,83\%) eram do sexo masculino, e 77 (45,56\%), do sexo feminino (Tabela 2), não sendo identificada diferença estatística entre sexo e reatividade ao teste sorológico $\left(\chi^{2}=0,53 ; \mathrm{p}=0,467\right)$. A idade mínima dos pacientes com reação sorológica para cisticerco de T. crassiceps foi de seis anos, e a máxima, de 89 anos, com média de 39 anos. Verificou-se que o percentual de reatividade aumentava com a idade, sendo $8,7 \%$ em crianças (até 10 anos) e 43,5\% na faixa etária maior de 50 anos (Tabela 3 ). Ao serem comparadas as pessoas com 50 anos de idade ou menos com aquelas com 50 anos ou mais, reativas e não reativas ao exame, observou-se significância estatística com $\chi^{2}=13,95$ e p = 0,0001, assim como também houve significância estatística ao se comparar a faixa etária de maiores de 50 anos com as demais faixas etárias: 0-10 $\operatorname{anos}\left(\chi^{2}=7,45 ; \mathrm{p}=0,0063\right), 11-20$ anos $\left(\chi^{2}=\right.$ $11,51 ; \mathrm{p}=0,0006)$ e $21-50$ anos $\left(\chi^{2}=5,60, \mathrm{p}=\right.$ 0,018).

Das 169 pessoas avaliadas, 77 (45,6\%) apresentavam queixas sugestivas de neurocisticercose, sendo mais evidente no sexo feminino $(29,0 \%)$ do que no masculino $(16,6 \%)$ e patente nas faixas etárias compreendidas entre as segunda e quinta décadas de vida $(30,8 \%)$. Desse total, $23(19,5 \%)$ foram reagentes à sorologia utilizada, sendo que $11,7 \%$ manifestavam sintomas há mais de 10 anos, $5,2 \%$ há menos de cinco anos e 2,6\% entre cinco e 10 anos. Entre os assintomáticos, 8,7\% foram também reagentes à sorologia. A queixa mais relata pela população estudada foi cefaléia persistente $(29,9 \%)$, seguida de convulsão e tontura e/ou alteração visual (ambos com freqüência de 6,5\%), síncope $(5,2 \%)$ e perturbação mental $(1,3 \%)$. Quando consideramos manifestações múltiplas, isto é, dois ou mais sintomas associados em uma
Tabela 2

Relação entre os resultados da reação sorológica de ELISA para C. cellulosae de amostras de soro e do sexo de indivíduos residentes no Município de João Costa, Piauí, Brasil.

\begin{tabular}{|c|c|c|c|c|c|c|}
\hline \multirow{2}{*}{$\begin{array}{l}\text { ELISA } \\
\text { (Sorologia) }\end{array}$} & \multicolumn{2}{|c|}{ Masculino } & \multicolumn{2}{|c|}{ Feminino } & \multicolumn{2}{|c|}{ Total } \\
\hline & $\mathrm{n}$ & $\%$ & $\mathrm{n}$ & $\%$ & $\mathrm{n}$ & $\%$ \\
\hline Reagentes & 9 & 5,3 & 14 & 8,3 & 23 & 13,6 \\
\hline Não reagentes & 69 & 40,8 & 77 & 45,6 & 146 & 86,4 \\
\hline Total & 78 & 46,2 & 91 & 53,8 & 169 & 100,0 \\
\hline
\end{tabular}

Tabela 3

Relação entre os resultados da reação sorológica de ELISA para C. cellulosae de amostras de soro e a faixa etária de indivíduos residentes no Município de João Costa, Piauí, Brasil.

\begin{tabular}{|c|c|c|c|c|c|c|}
\hline \multirow{3}{*}{$\begin{array}{l}\text { Faixa etária } \\
\text { (em anos) }\end{array}$} & \multicolumn{4}{|c|}{ Sorologia } & \multicolumn{2}{|c|}{ Total } \\
\hline & \multicolumn{2}{|c|}{ Reagente } & \multicolumn{2}{|c|}{ Não reagente } & & \\
\hline & $n$ & $\%$ & $n$ & $\%$ & $n$ & $\%$ \\
\hline $0-10$ & 2 & 8,7 & 28 & 19,2 & 30 & 17,7 \\
\hline $11-20$ & 4 & 17,4 & 54 & 37,0 & 58 & 34,3 \\
\hline $21-50$ & 7 & 30,4 & 46 & 31,5 & 53 & 31,4 \\
\hline$>50$ & 10 & 43,5 & 18 & 12,3 & 28 & 16,6 \\
\hline Total & 23 & 100,0 & 146 & 100,0 & 169 & 100,0 \\
\hline
\end{tabular}

mesma pessoa, a freqüência de sintomas aumenta para $50,7 \%$ (Tabela 4 ).

O percentual de soro-reatividade foi elevado para os que se queixaram de cefaléia persistente, na sua forma isolada, e para os que apresentavam sintomas múltiplos, sugestivos de neurocisticercose $(30,4 \%)$. Outro fato que chama a atenção, é que um percentual elevado de pessoas $(34,8 \%)$ dentre os reagentes não apresentava sintomas sugestivos de neurocisticercose (Tabela 5).

No segundo momento do estudo, das 92 pessoas analisadas, $36(40,0 \%)$ tinham idade inferior a 20 anos, e $56(60,0 \%)$, idade acima de 20 anos, sendo que $51(55,0 \%)$ eram do sexo masculino, e 41 (45,0\%), do sexo feminino.

Os resultados obtidos pelos métodos de ELISA e WB para pesquisa de anticorpos anticisticerco de $T$. crassiceps no soro mostraram reatividade de $24,0 \%$ (22 pessoas) e de $29,0 \%$ (27 pessoas), respectivamente. Não houve diferença estatística em relação à reatividade pelos diferentes métodos entre os sexos: homens (ELISA $20,0 \%$; WB - 36,0\%) e mulheres (ELISA - 29,0\%; 
Tabela 4

Freqüência de manifestações clínicas sugestivas de neurocisticercose em indivíduos residentes do Município de João Costa, Piauí, Brasil.

\begin{tabular}{lrr}
\hline Sintomatologia & \multicolumn{2}{c}{ Freqüência } \\
& $\mathrm{n}$ & $\%$ \\
\hline Cefaléia persistente & 23 & 29,9 \\
Convulsão & 5 & 6,5 \\
Tonteira e/ou alteração visual & 5 & 6,5 \\
Síncope & 4 & 5,2 \\
Perturbação mental & 1 & 1,3 \\
Sintomas múltiplos* & 39 & 50,6 \\
Total & 77 & 100,0
\end{tabular}

* Cefaléia persistente e/ou convulsão e/ou tontura e/ou alteração visual e/ou síncope e/ou perturbação mental.

Tabela 5

Freqüência de manifestações clínicas sugestivas de neurocisticercose em indivíduos residentes do Município de João Costa, Piauí, Brasil, que apresentam sorologia positiva para cisticercos de Taenia crassiceps.

\begin{tabular}{lrr}
\hline Sintomatologia & \multicolumn{2}{c}{ Reagentes } \\
& $\mathrm{n}$ & $\%$ \\
\hline Cefaléia persistente & 7 & 30,4 \\
Perturbação mental & 1 & 4,4 \\
Sintomas múltiplos & 7 & 30,4 \\
Sem sintomas & 8 & 34,8 \\
Total & 23 & 100,0 \\
\hline
\end{tabular}

$\mathrm{WB}-21,0 \%)$. Houve diferença significativa entre as faixas etárias de 0 a 20 anos e de maiores de 20 anos, com resultados de reatividade no ELISA de 11,0\% (04 indivíduos) e 33,0\% (18 indivíduos) e no WB de 5,0\% (02 indivíduos) e 45,0\% (25 indivíduos), respectivamente (Figura 1), com $\chi^{2}=$ 5,33 e $\mathrm{p}=0,02$ para o ELISA e $\chi^{2}=16,15$ e $\mathrm{p}=$ 0,00006 para o WB. Não foi possível utilizarmos a mesma distribuição etária do primeiro momento, pela necessidade de agruparmos as faixas, em virtude do número muito reduzido de casos.

Na população estudada nesse segundo momento, de 13 famílias, 11 apresentavam pelo menos um de seus membros com sorologia reagente para cisticercose, e 4 tinham mais de um indivíduo reator pela pesquisa de anticorpos anticisticerco de T. crassiceps. Em oito $(61,5 \%)$ dessas residências, havia a criação de suínos soltos e ao redor das residências. Apenas 7,7\% dessas casas utilizavam água encanada; as demais utilizavam água obtida de poços comunitários ou de açudes, armazenando-a em potes de barro cobertos com panos. A atividade econômica predominante nessas famílias era a lavoura de pequeno porte (77,0\% das famílias), de subsistência, na qual há a participação de todos os membros da casa.

Das 701 pessoas avaliadas pelo exame parasitológico de fezes, observou-se uma proporção de parasitismo intestinal de 51,0\%. A freqüência de protozoários foi bem superior à freqüência de helmintos (95,0\% vs. 5,0\%), considerando-se o valor total de 609 parasitos em indivíduos monoparasitados e poliparasitados (Tabela 6). A maior freqüência de parasitismo observada foi de Entamoeba coli (29,0\%) e de Entamoeba histolytica/Entamoeba dispar (23,0\%), tendo sido detectado apenas um caso de teníase, sem diferenciação da espécie. Pelos critérios atuais, E. coli, E. nana e Iodamoeba butschlii são consideradas amebas que parasitam o intestino humano 15,16. A presença de mais de um parasito foi observada nas amostras fecais de 173 pessoas, correspondendo a $24,7 \%$ do material examinado.

\section{Discussão}

O encontro de anticorpos antilarva de T. crassiceps nas amostras de soro dos indivíduos da população estudada sugere a ocorrência da cisticercose nessa área. Entretanto, tomando-se como base a natureza do processo de seleção dos participantes do estudo que integraram a amostra, os valores encontrados possivelmente representam superestimativas da realidade.

No Brasil, estudos sobre o tema têm sido relatados nos Estados de São Paulo e Minas Gerais 4,17. Em estudos soroepidemiológicos em diferentes regiões do Brasil, encontrou-se uma freqüência de infecção variando de 3,7 a 8,1\% 18. A freqüência no nordeste brasileiro tem sido considerada baixa, refletindo, certamente, a inadequação do diagnóstico desse processo infeccioso na região 19 . Um estudo retrospectivo no Hospital São José, hospital de referência para doenças infecciosas e parasitárias no Ceará, mostrou que, entre 1988 e 1994, 119 pacientes tiveram o diagnóstico de neurocisticercose 3 . No nosso estudo, foi encontrada uma positividade elevada de anticorpos anti-cisticerco (23,0\%), mas que não reflete a prevalência real de cisticercose na população geral, porque as amostras de soro foram obtidas de um grupo 
selecionado a partir de dados epidemiológicos e laboratoriais compatíveis com a aquisição da doença.

Estudos epidemiológicos sobre cisticercose, realizados em países em desenvolvimento com elevada freqüência de outras helmintoses, mostraram que a utilização de testes imunológicos com alta especificidade é de grande importância 20 . Devido à alta homologia dos antígenos da larva da T. solium aos da T. crassiceps, esses últimos têm sido utilizados nos métodos imunológicos empregados para o diagnóstico da cisticercose. As técnicas ELISA e WB, empregando esses antígenos, têm apresentado elevadas sensibilidade e especificidade em amostras de soro 21,22, líquido cefaloraquidiano 13 ou de sangue total 11 .

A freqüência de anticorpos antilarva de $T$. crassiceps entre mulheres e homens não apresentou diferença estatisticamente significativa, concordando com os achados na Paraíba e no Equador 19. Por outro lado, vários pesquisadores encontraram associação entre soro-reatividade e sexo feminino 5,17. O desenvolvimento ou a suscetibilidade dessa doença possivelmente sofreria influência de hormônios femininos 23 , mas são necessários estudos mais específicos sobre o tema para tal conclusão. Nesse estudo, as mulheres apresentaram uma freqüência maior de sintomas relacionados à neurocisticercose do que os homens, fato esse também observado no México 7,24. Outros autores têm verificado que algumas formas de neurocisticercose são mais graves em mulheres 25,26. Nesse estudo, não foi avaliada essa possível associação.

A cisticercose pode ser observada em qualquer faixa etária, sendo mais freqüente entre a terceira e quarta décadas de vida 27 ou entre a terceira e quinta décadas de vida 28 . Observouse uma freqüência maior de soros reagentes em pessoas com idade acima de vinte anos, o que pode sugerir que ela se comporta segundo o padrão das doenças crônicas, em que quanto mais avançada a idade, maior chance da doença se manifestar. Além disso, a multiplicidade de exposições ao longo da vida aumentaria a probabilidade de infecção, com um risco cumulativo.

Embora a cisticercose seja uma doença que siga os padrões de doença crônica, é significativa a freqüência de resultados reagentes encontrados em crianças com até 10 anos de idade no Município de João Costa $(8,7 \%$ no primeiro momento e $17,0 \%$ no segundo). Esse resultado pode estar relacionado, principalmente, à falta de hábitos higiênicos apresentada por grande parte das famílias de crianças, as-
Figura 1

Análise do resultado do método de WB-ConATcra e ELISA-ConATcra em relação à faixa etária da população estudada no Município de João Costa, Piauí, Brasil.

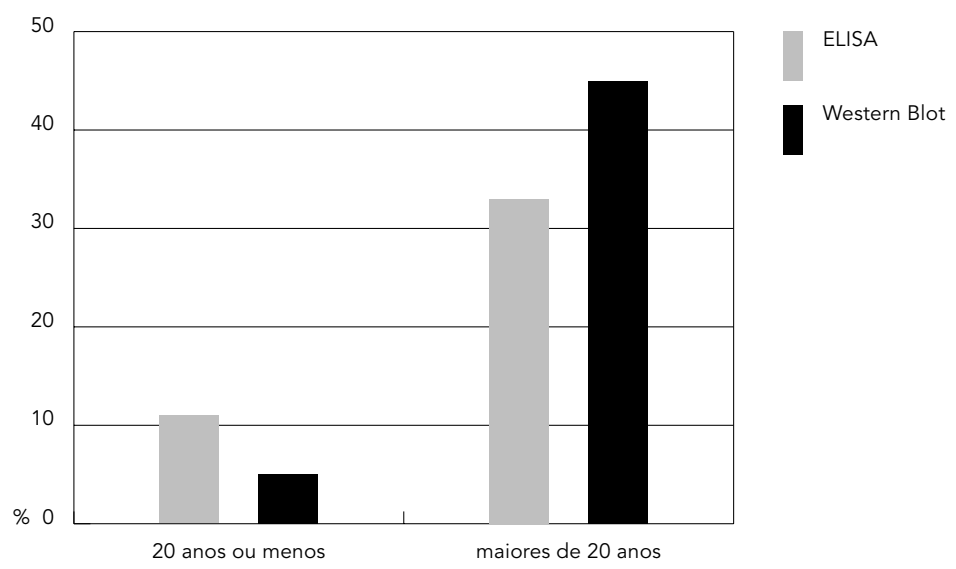

Tabela 6

Prevalência das parasitoses intestinais em 701 amostras de fezes coletadas de indivíduos residentes no Município de João Costa, Piauí, Brasil.

\begin{tabular}{lrr} 
& Total & $\%$ \\
\hline Positivo & 360 & 51,4 \\
Negativo & 341 & 48,6 \\
Entamoeba coli & 206 & 29,0 \\
Entamoeba histolyca & 158 & 23,0 \\
Endolimax nana & 68 & 10,0 \\
lodamoeba butschlii & 71 & 10,0 \\
Giardia lamblia & 26 & 4,0 \\
Blastocistis hominis & 51 & 7,0 \\
Taenia sp. & 1 & 0,1 \\
Hymenolepis nana & 5 & 0,7 \\
Ascaris lumbricoides & 1 & 0,1 \\
Ancilostomídeo & 19 & 3,0 \\
Strongyloides stercoralis & 1 & 0,1 \\
Enterobius vermicularis & 2 & 0,3 \\
Protozoário & 580 & 95,0 \\
Helminto & 29 & 5,0 \\
\hline
\end{tabular}


sociada às carências nutricionais. A neurocisticercose não é rara em crianças, mas tem sido pouco estudada nessa população 29 .

O caráter crônico da neurocisticercose humana acarreta, em alguns casos, sintomas tardios. Nesse estudo, a presença de sintomas foi mais evidente entre as segunda e quinta décadas de vida, o que se aproxima do verificado no México, onde a maior freqüência estava entre as terceira e quarta décadas de vida 27 .

Entre as pessoas reagentes para cisticercose no Município de João Costa na primeira fase do estudo, 46,7\% queixavam-se de cefaléia. Esse percentual varia em diferentes regiões, como $33,0 \%$ no México 30 e $70,6 \%$ no Estado do Paraná 5 . A cefaléia também tem sido referida como um dos sintomas mais freqüentes da neurocisticercose por outros autores 31 .

Além da cefaléia, outras queixas sugestivas de neurocisticercose foram freqüentes: convulsão, tonteira e/ou alteração visual e síncope, diferindo das observações no México, onde a principal queixa foi alteração visual seguida de cefaléia 30. Convulsão aparece apenas como a sexta queixa referida, diferente, portanto, de nossa casuística em que foi a segunda queixa mais freqüente. A importância da convulsão reflete-se na indicação da neurocisticercose como uma das principais causas de epilepsia em áreas endêmicas para o complexo teníasecisticercose 32,33

Segundo a Organização Mundial da Saúde (OMS) 34 , a estimativa de prevalência global de convulsões está entre 2,0 e 5,0\%, tendendo a aumentar nas regiões com saneamento precário, em consonância com o percentual de convulsão encontrado nesse estudo (10,1\%).

A distribuição dos parasitos intestinais varia bastante de região para região, em conseqüência de fatores, tais como, sanitários e educacionais 35 , contato com água contaminada 36 , atividade profissional 37 , hábito de ingerir verduras e legumes crus 37, condições ambientais e susceptibilidade genética. No Piauí, encontramos regiões com alta 38 e baixa prevalência de helmintos 8. Quanto aos protozoários intestinais, o presente estudo identificou elevadas freqüências, principalmente daqueles de importância médica como a E. histolytica/E. dispar $8,11,39$.

Apenas um caso de teníase foi detectado nas 701 amostras de fezes analisadas. Em outros estudos realizados em diferentes regiões do Brasil, a presença de ovos de Taenia sp. também foi observada em número reduzido nas amostras fecais $38,39,40,41$. Trabalhos realizados em regiões endêmicas para teníase-cisticercose humana no México também revelaram baixas freqüências de teníase pelo exame parasitológico, uma vez que o método tem baixa sensibilidade, principalmente para a parasitose causada pela $T$. solium 24,42 . Uma explicação para essa baixa sensibilidade é a liberação intermitente das proglotes que não são dispersas uniformemente nas fezes. Por essa razão, alguns trabalhos têm sugerido que sejam utilizadas técnicas imunológicas, como ELISA, para a pesquisa de coproantígenos como método alternativo para o diagnóstico da teníase 43 .

Os resultados apontam para questões graves, como a elevada freqüência de protozoários intestinais de grande importância médica como a amebíase, a existência das manifestações associadas ao complexo teníase-cisticercose e a ausência de diagnóstico específico da cisticercose humana, levando ao consumo, muitas vezes desnecessário, de anticonvulsivantes. Esses resultados são o reflexo das condições observadas no município estudado geradas pela forma de ocupação e organização social do espaço ao longo de mais de três séculos de história 10 . Nesse sentido, condições sanitárias precárias, falta de higiene, relação estreita com várias espécies de animais, defecação próxima às residências, criação de suínos em liberdade e falta de inspeção das carnes consumidas são situações que integram um contexto epidemiológico que favorece o processo de transmissão de diferentes parasitoses intestinais e da neurocisticercose, dentre outras. 


\section{Resumo}

Integrando as pesquisas sobre parasitoses na região do entorno do Parque Nacional Serra da Capivara, Piauí, Brasil, realizadas entre 1999 e 2001, o presente estudo tem como objetivo avaliar a situação epidemiológica da cisticercose humana no Município de João Costa, no Nordeste do Brasil. Foram obtidas informações clínico-epidemiológicas e coletadas amostras de sangue para testes sorológicos imunoenzimáticos (ELISA e Western blot), empregando cisticercos de Taenia crassiceps como antígeno. Na primeira etapa, em 1999, foram investigadas 169 pessoas com história confirmada ou suspeita de infecção/doença pelo complexo teníase-cisticercose, e seus familiares. Na análise, 13,6\% das pessoas apresentaram soros reagentes para cisticercose pelo método ELISA. Na segunda etapa, em 2001, foram avaliadas 92 amostras de soro de indivíduos reativos para cisticercose detectados no primeiro momento e seus familiares, sendo que $24,0 \%$ das amostras de soro foram reagentes para cisticercose pelo ELISA, e 29,0\%, pelo WB. Nessa mesma etapa, realizou-se inquérito coprológico em 701 pessoas, incluindo voluntários. A prevalência de parasitoses intestinais foi de 51,0\%, tendo sido observada uma maior prevalência de protozoários $(95,0 \%)$ em relação aos helmintos (5,0\%). Os resultados do estudo indicam o caráter endêmico da cisticercose na área, além da elevada freqüência de protozooses intestinais.

Teníase; Anticorpos; Doenças Parasitárias

\section{Agradecimentos}

Ao suporte da Fundação Museu do Homem Americano para desenvolvimento da pesquisa de campo e à equipe de funcionários da Fundação Nacional de Saúde dos municípios de São Raimundo Nonato e de São João do Piauí Financiamento: Conselho Nacional de Desenvolvimento Científico e Tecnológico/Programa Universal; Fundação Oswaldo Cruz/Programa de Apoio à Pesquisa Estratégica em Saúde; Escola de Governo, Escola Nacional de Saúde Pública, Fundação Oswaldo Cruz.

\section{Colaboradores}

A. N. Ramos Jr. foi responsável pela coleta das informações e preenchimento dos formulários e participou da preparação do manuscrito. H. W. Macedo foi responsável pela coleta de material e execução dos exames e participou da preparação do manuscrito. M. C. Rodrigues foi responsável pelas coletas de dados e das amostras de sangue. R. H. S. Peralta foi responsável pela coleta das amostras de sangue e execução dos ensaios de ELISA e Immunoblot e participou da preparação do manuscrito. N. C. Marques foi responsável pela análise estatística. M. C. Marques realizou a leitura das lâminas do exame parasitológico de fezes. J. R. Alves e A. N. Paes foram responsáveis pela distribuição, recolhimento e preparação das amostras do exame parasitológico de fezes. J. A. F. Castro foi responsável pelo atendimento e pelos dados clínicos de casos com sintomatologia sugestiva de neurocisticercose. A. J. G. Araújo foi responsável pelo desenho do estudo e pela análise dos exames parasitológicos e participou da revisão do manuscrito. J. M. Peralta coordenou os estudos de sorologia e a discussão dos resultados e participou da revisão do manuscrito.

\section{Referências}

1. Fontbonne A, Freese-de-Carvalho E, Acioli MD, Sá GA, Cesse EAP. Fatores de risco para poliparasitismo intestinal em uma comunidade indígena de Pernambuco. Cad Saúde Pública 2001; 17:367-73.

2. Del Brutto OH, Rajshekhar V, White Jr. AC, Tsang VCW, Nash TE, Takayanagui OM, et al. Proposed diagnostic criteria for neurocysticercosis. Neurology 2001; 57:177-83.

3. Sousa AQ, Sá HLC, Queiroz TRBS, Horta WG, Pearson RD. Neurocysticercosis in Ceará state, northeastern Brazil: a review of 119 cases. Am J Trop Med Hyg 1998; 58:759-62.

4. Silva-Vergara ML, Vieira CO, Castro JH, Micheletti LG, Otaño AS, Franquini Jr. J, et al. Achados neurológicos e laboratoriais em população de área endêmica para teníase-cisticercose, Lagamar, MG, Brasil (1992-1993). Rev Inst Med Trop São Paulo 1994; 36:335-42.

5. Lonardoni MVC, Bertolini DA, Silveira TGV, Arraes SMAA, Svidzinski TIE; Cardoso RF, et al. Freqüência de anticorpos anti-Cysticercus cellulosae em indivíduos de cinco municípios da região Norte do Estado do Paraná, Brasil. Rev Saúde Pública 1996; 30:273-9.

6. Agapejev S. Epidemiology of neurocysticercosis in Brazil. Rev Inst Med Trop São Paulo 1996; 38: 207-16.

7. Pereira LRM. Prevalência da teníase humana (Tae- 
nia sp.) na área rural do Município de Altos, Piauí [Monografia]. Rio de Janeiro: Escola Nacional de Saúde Pública, Fundação Oswaldo Cruz; 1995.

8. Ramos Jr. AN, Macedo HW, Chieffi PP, Gonçalves MLC, Carvalho DM, Alves JR, et al. Sobre o resultado de exames parasitológicos de fezes em povoados do entorno do Parque Nacional da Serra da Capivara, Sudeste do Piauí: um paradoxo. Ciênc Saúde Coletiva 2000; 5 Suppl:468-9.

9. Fundação Instituto Brasileiro de Geografia e Estatística. Estimativa da população - 2003. Resolução no 2, de 25 de agosto de 2003. Diário Oficial da União 2003; 30 ago.

10. Ramos Jr. AN. Epidemiologia da endemia chagásica no Município de João Costa, Sudeste do Piauí, Brasil [Dissertação de Mestrado]. Rio de Janeiro: Núcleo de Estudos de Saúde Coletiva, Universidade Federal do Rio de Janeiro; 2001.

11. Peralta RHS, Vaz AJ, Macedo HW, Peralta JM. Using whole blood collected on filter paper detection of anti-cysticercus antibodies. Trans R Soc Trop Med Hyg 2001; 95:1-2.

12. Vaz A, Nunes C, Piazza RMF, Livramento JA, Nakamura PM, Ferreira AW. Immunoblot with cerebrospinal fluid from patients with neurocysticercosis using antigen from cysticerci of Taenia solium and Taenia crassiceps. Am J Trop Med Hyg 1997; 57:354-7.

13. Pardini AX, Peralta RHS, Vaz AJ, Machado LR, Peralta JM. Use of Taenia crassiceps cysticercus antigen preparations for detect of antibodies in cerebrospinal fluid samples from patients with neurocysticercosis (Taenia solium). Clin Diagn Lab Immunol 2002; 9:190-3.

14. Teixeira MGM, Borges-Pereira J, Netizert E, Souza MLNX, Peralta JM. Development and evaluation of an enzyme linked immunotransfer blot technique for serodiagnosis of Chagas' disease. Trop Med Parasitol 1994; 45:308-12.

15. Araújo A, Jansen AM, Bouchet F, Reinhard K, Ferreira LF. Parasitism, the diversity of life, and paleoparasitology. Mem Inst Oswaldo Cruz 2003; 98 Suppl 1:5-11.

16. Rey L. Parasitologia. $3 \underline{a}$ Ed. Rio de Janeiro: Editora Guanabara Koogan; 2001.

17. Vaz AJ, Hanashiro ASG, Chieffi PP, Ferreira AW. Freqüência de indivíduos com anticorpos séricos anti-Cysticercus cellulosae em cinco municípios do Estado de São Paulo. Rev Soc Bras Med Trop 1990; 23:97-9.

18. Ferreira MS, Costa-Cruz JM, Nishioka SA, Mantese E, Castro MRF, Gonçalves-Pires LPM. Neurocysticercosis in Brazilian children: report of 10 cases. Trop Med Parasitol 1994; 45:49-50.

19. Gonçalves-Coelho TD, Coelho MD. Neurocysticercosis in Paraíba, northeast Brazil. An endemic area? Arq Neuropsiquiatr 1996; 54:565-70.

20. Tsang VCW, Wilson M. Taenia solium cysticercosis: an under-recognized but serious public health problem. Parasitol Today 1995; 11:124-6.

21. Macedo HW, Peralta RHS, Cipriano A, Sarmento MR, Vaz AJ, Peralta JM. Avaliação de testes imunológicos para o diagnóstico da neurocisticercose. J Bras Patol Med Lab 2002; 38:93-103.

22. Peralta RHS, Vaz AJ, Pardini A, Macedo HW, Simone LR, Salvatori G, et al. Evaluation of an anti- gen from Taenia crassiceps cysticercus's for the serodiagnosis of neurocysticercosis. Acta Trop 2002; 83:159-68.

23. Rangel R, Torres B, Del Brutto OH, Sotelo J. Cysticercotic encephalitis: a severe form in young females. Am J Trop Med Hyg 1987; 36:387-92.

24. Sarti E, Schantz PM, Plancarte A. Prevalence and risk factors for Taenia solium taeniasis and cysticercosis in humans and pigs in a village in Morelos, Mexico. Am J Trop Med Hyg 1992; 46:677-85.

25. Diaz-Camacho S, Candil A, Uribe M, Wilms K. Serology as an indicator of Taenia solium tapeworm infections in a rural community in Mexico. Trans R Soc Trop Med Hyg 1990; 84:563-6.

26. Sotelo J, Marin C. Hydrocephalus secondary to cysticercotic arachnoiditis. A long-term followup review of 92 cases. J Neurosurg 1987; 66:686-9.

27. Rodrigues-Carbajal J, Palacios E, Azar-Kia B, Churchill R. Radiology of cysticercosis of the central nervous system including computed tomography. Radiology 1977; 125:127-31.

28. Schenone H, Vilarroel F, Rojas A, Ramirez R. Epidemiology of human cysticercosis in Latin America. In: Flisser A, Willms K, Laclette JP, Larralde C, Ridaura C, Beltran F, editors. Cysticercosis: present state of knowledge and perspectives. New York: Academic Press; 1982. p. 25-38.

29. Rebolledo FA. Perfil de la neurocysticercosis em niños mexicanos. Cirugía y Cirujanos 1998; 66:89-99.

30. Sarti E, Schantz PM, Lara-Aguilera R, GomezDantes H, Flisser A. Taenia solium taeniasis and cysticercosis in a Mexican village. Trop Med Parasitol 1988; 39:194-98.

31. Tsung J, Tsung SS, Cholovsky S. Cerebral cysticercosis. Indiana Med 1986; 79:600-2.

32. Trevisol-Bittencourt PC, Silva NC, Figueiredo R. Neurocisticercose em pacientes internados por epilepsia no Hospital Regional de Chapecó, região Oeste do Estado de Santa Catarina. Arq Neuropsiquiatr 1998; 56:53-8.

33. Vianna LG, Macedo V, Mello P, Costa JM, Yoo JM. Estudo clínico e laboratorial da neurocisticercose em Brasília. Rev Bras Neurol 1990; 26:35-40.

34. World Health Organization. Epilepsy: etiology, epidemiology and prognosis. Geneva: World Health Organization; 2001.

35. Castello Branco Jr. A, Rodrigues JC. Importância de aspectos sanitários e educacionais na epidemiologia de enteroparasitoses em ambientes rurais. Rev Bras Anal Clin 1999; 31:87-90.

36. Gross R, Schell B, Molina MC, Leão MA, Strack U. The impact of improvement of water supply and sanitation facilities on diarrhea and intestinal parasites: a Brazilian experience with children in two low-income urban communities. Rev Saúde Pública 1989; 23:214-20.

37. Carvalho JB, Nascimento ER, Ribeiro VR, Nogueira Neto JF, Carvalho IS, Carvalho FS, et al. Presença de ovos de helmintos em hortaliças fertilizadas com lodo de lagoa de estabilização. Rev Bras Anal Clin 2003; 35:101-3.

38. Oliveira MF, Costa STCB, Bezerra FSM. Incidência de enteroparasitos na zona rural do município de Parnaíba, Piauí. Rev Bras Anal Clin 2001; 33:45-8.

39. Alves JR, Macedo HW, Ramos Jr. AN, Ferreira LF Gonçalves MLC, Araújo A. Parasitoses intestinais 
em região semi-árida do Nordeste do Brasil: resultados preliminares distintos das prevalências esperadas. Cad Saúde Pública 2003; 19:667-70.

40. De Carli GA, Spalding SM, Rott M, Ribeiro L, Chaves A, Silva AMC, et al. Incidência de enteroparasitos entre colonos sem-terra nos assentamentos de Charqueadas e Capela de Santana no Estado do Rio Grande do Sul. Rev Bras Anal Clin 1994; 26:123-5.

41. De Carli GA, Mentz M, Rott MB, Silva ACA, Wendorff A, Tasca T, et al. Prevalência das enteroparasitoses nas vilas periféricas da grande Porto Alegre, nos assentamentos de trabalhadores rurais e na cidade de Arroio dos Ratos no Estado do Rio Grande do Sul. Rev Bras Anal Clin 1997; 29:185-9.

42. Sarti E, Schantz PM, Plancarte A, Wilson M, Gutierrez IO, Aguilera J, et al. Epidemiological investigation of Taenia solium taeniasis and cysticercosis in a rural village of Michoacan state, Mexico. Trans R Soc Trop Med Hyg 1994; 88:49-52.

43. Allan JC, Velásquez TM, Torres-Alvarez R, Yurrita P, Garcia-Noval J. Field trial of the coproantigenbased diagnosis of Taenia solium taeniasis by enzyme-linked immunosorbent assay. Am J Trop Med Hyg 1996; 54:352-6.

Recebido em 12/Fev/2004

Versão final reapresentada em $07 / \mathrm{Jun} / 2004$

Aprovado em 09/Jun/2004 